\title{
- Mesospheric Non-Migrating Tides Generated With Planetary Waves: II Influence of Gravity Waves
}

\author{
H. G. Mayr, J. G. Mengel., E. L. Talaat, H. S. Porter, K. L. Chan \\ ${ }^{1}$ Goddard Space Flight Center, Greenbelt, MD, 20771 \\ ${ }^{2}$ Science Systems \& Applications, Inc., Lanham, MD \\ ${ }^{3}$ Applied Physic Laboratory, Johns Hopkins University, Laurel, MD \\ ${ }^{4}$ Furman University, Greenville, SC \\ ${ }^{5}$ Hong Kong University of Science and Technology, Hong Kong, China
}

Prepared

For

Journal of Atmospheric and Solar Terrestrial Physics

July 2003 
Mesospheric Non-Migrating Tides Generated With Planetary Waves: II Influence of Gravity Waves

H. G. Mayr, J. G. Mengel., E. L. Talaat, H. S. Porter, K. L. Chan

${ }^{1}$ Goddard Space Flight Center, Greenbelt, MD, 20771

${ }^{2}$ Science Systems \& Applications, Inc., Lanham, MD

${ }^{3}$ Applied Physic Laboratory, Johns Hopkins University, Laurel, MD

${ }^{4}$ Furman University, Greenville, SC

${ }^{5}$ Hong Kong University of Science and Technology, Hong Kong, China

Popular Summary: We demonstrated that, in our model, non-linear interactions between planetary waves (PW) and migrating tides could generate in the upper mesosphere non-migrating tides with amplitudes comparable to those observed. The Numerical Spectral Model (NSM) we employ incorporates Hines' Doppler Spread Parameterization for small-scale gravity waves (GW), which affect in numerous ways the dynamics of the mesosphere. The latitudinal (seasonal) reversals in the temperature and zonal circulation, which are largely caused by GWs (Lindzen, 1981), filter the PWs and contribute to the instabilities that generate the PWs. The PWs in turn are amplified by the momentum deposition of upward propagating GWs, as are the migrating tides. The GWs thus affect significantly the migrating tides and PWs, the building blocks of non-migrating tides. In the present paper, we demonstrate that GW filtering also contributes to the non-linear coupling between PWs and tides. Two computer experiments are presented to make this point. In one, we simply turn off the GW source to show the effect. In the second case, we demonstrate the effect by selectively suppressing the momentum source for the $\mathrm{m}=0$ non-migrating tides. 
- $\quad$ Abstract: We demonstrated that, in our model, non-linear interactions between planetary waves (PW) and migrating tides could generate in the upper mesosphere non-migrating tides with

- amplitudes comparable to those observed. The Numerical Spectral Model (NSM) we employ incorporates Hines' Doppler Spread Parameterization for small-scale gravity waves (GW), which affect in numerous ways the dynamics of the mesosphere. The latitudinal (seasonal) reversals in the temperature and zonal circulation, which are largely caused by GWs (Lindzen, 1981), filter the PWs and contribute to the instabilities that generate the PWs. The PWs in turn are amplified by the momentum deposition of upward propagating GWs, as are the migrating tides. The GWs thus affect significantly the migrating tides and PWs, the building blocks of non-migrating tides. In the present paper, we demonstrate that GW filtering also contributes to the non-linear coupling between PWs and tides. Two computer experiments are presented to make this point. In one, we simply turn off the GW source to show the effect. In the second case, we demonstrate the effect by selectively suppressing the momentum source for the $m=0$ non-migrating tides.

\section{Introduction}

Measurements from the ground (e.g., Avery et al., 1989; Manson et al., 1989; Vincent et al., 1989) and with the UARS spacecraft (Hays et al., 1994; McLandress et al., 1996; Burrage et al., 1995a, b) have shown that the diurnal tides in the mesosphere and lower thermosphere exhibit large seasonal variations.

The observations mainly refer to the dominant tides that propagate westward with the Sun. In the upper mesosphere, however, the nonmigrating tides (i.e., tides not propagating with the Sun) are also important. Nonmigrating tides can be generated by solar insolation of tropospheric water vapor and stratospheric ozone (the main sources for migrating tides), and by latent heat release as well as convective or sensible heating. But these excitation processes alone cannot reproduce the observed amplitudes (e.g., Miyahara et al., 1993; Hagan et al., 1997).

As alternative excitation mechanism, Waltersheid et al. (1986) thus suggested that gravity wave interactions with migrating tides could be important. Teitelbaum and Vial (1991) proposed that non-linear interactions between migrating tides and planetary waves could produce sizable nonmigrating tides, and this mechanism has been explored by a number of investigators. Forbes et al. (1995) observed a westward propagating 12-hour wave in the radar measurements near the north pole and suggested that it is produced by nonlinear interactions between the solar driven 
- migrating semidiurnal tide and stationary $\mathrm{m}=1$ planetary waves. Based on an analysis of UARS High Resolution Doppler Imager (HRDI) measurements over a period of four years, Talaat and

- Lieberman (1999) observed for the diurnal (24 hour) tide above $80 \mathrm{~km}$ large amplitudes in the zonal wave number $\mathrm{m}=0$ and nonmigrating components in $\mathrm{m}=1-3$ that were as large as the migrating tide during some seasons. They suggested that planetary wave interactions may account for these nonmigrating tides. Miyahara et al. (1999) found that nonlinear interactions between waves could produce the nonmigrating tides in their model. Based on simulations with the TIME-GCM model, Hagan and Roble (2001) suggested that non-linear interactions between the migrating diurnal tide and $\mathrm{m}=1$ planetary waves could produce measurable non-migrating tides in the upper mesosphere.

We recently demonstrated for the $m=0$ diurnal tide in our model that the planetary wave mechanism can generate tidal amplitudes that are comparable to those observed in the mesosphere (Mayr et al., 2003). In the accompanying paper (Part I), we discuss more fully the nonmigrating tides, and in particular their seasonal variations. In the study presented here, we shall focus on the influence of gravity waves. We shall discuss two modeling experiments that are designed to show how GWs can affect the nonmigrating tides and how the waves contribute to generate the non-linear coupling between PWs and westward migrating tides that is involved.

\section{Mesospheric Gravity Wave Processes}

With emphasis on gravity wave processes, we illustrate in Figure 1 (similar to Figure 19 in Part I) the important dynamical interactions that produce non-migrating tides. In the model, solar heating drives: (a) the westward migrating tides, and (b) the mean zonal circulation and associated temperature variations (zonal wave number $\mathrm{m}=0$ ). As demonstrated first by Lindzen (1981), GWs cause the zonal winds and latitudinal (seasonal) temperature variations to reverse at higher altitudes in the mesosphere (item 1 in Figure 1). The waves have also been shown to cause the observed reversal in the phase of the semiannual oscillation (SAO) at low latitudes (Dunkerton, 1978). The GW induced changes in the temperature, pressure, and wind fields produce instabilities that have been invoked to generate PWs in the mesosphere (e.g., Plumb, 1983). Filtered by the seasonally varying global-scale zonal-mean $(m=0)$ circulation and temperature variations, upward propagating GWs deposit momentum in the tides and thus contribute to the observed seasonal variations with large amplitude maxima around equinox (2). 
Gravity waves have also been invoked to account for the non-linear interactions between the diurnal and semidiurnal tides. Apart from the important role GWs play in generating the PWs

- through the mean zonal circulation (1), GWs are also involved in amplifying the PWs (3). Gravity wave breaking causes momentum deposition in vertical wind shears, which is the process that can generate the Quasi Biennial Oscillation $(\mathrm{QBO})$ and contributes to produce the large Semiannual Oscillations (SAO) in the middle atmosphere at low latitudes (4).

We had argued earlier (Mayr et al., 1999, 2001, 2002) that GW filtering could produce nonlinear interactions to affect the dynamical features of the mesosphere. Gravity wave filtering appears to be a natural candidate for generating non-linear interactions between the QBO and $\mathrm{SAO}$ to produce inter-seasonal variations in the upper mesosphere, between the $\mathrm{QBO}$ and the $\mathrm{AO}$ (annual oscillation) to produce quasi-decadal oscillations, and between the diurnal and semidiurnal tides referred to above. Having shown in Part I that non-linear coupling between migrating tides and PWs generates in the NSM non-migrating tides with substantial amplitudes, we are asking the question to what extent GWs contribute to produce the nonlinearities involved (item 5 in Figure 1).

With Figure 2 we illustrate how GW filtering may produce non-linear coupling between PWs and tides to generate non-migrating tides. For this purpose, we consider an upward propagating GW that deposits some of its eastward momentum into the eastward (positive) winds of a quasistationary long-period PW it encounters. The wave momentum thus given to the $\mathrm{PW}$ is then missing in the GW when it encounters the tide, which is illustrated with an arrow to the left (reduced eastward momentum). This PW induced deficit in the GW momentum becomes effective when the GW interacts with the tide. The deficit of eastward momentum in the GW would selectively reduce the eastward phase of the tide (relative to the westward phase) - and a similar argument applies to the westward winds of the PW that would reduce the eastward phase of the tide. The net result of this interaction is that the tide, its periodicity virtually intact, is modulated by the $\mathrm{PW}$, which is the signature of a non-linear interaction. This illustrates the nonlinear interaction for the temporal variations of PWs and tides, and similar arguments could be applied for the non-linearity that couples the longitudinal variations of PWs and tides. 


\section{Numerical Spectral Model}

The Numerical Spectral Model (NSM), discussed in greater details in Part I, extends from the Earth' surface up into the thermosphere were homogeneous boundary conditions apply, and its design and applications have been extensively discussed in the literature (e.g., Chan et al., 1993; Mengel et al., 1994; Mayr et al., 1997, 1998, 2001). The tides in this model are only excited by the classical westward migration sources in the troposphere and stratosphere (Forbes and Garret, 1975), i.e., without accounting for the non-migrating sources associated with topography and convection in the troposphere. The planetary waves in the NSM are excited by instabilities and amplified by GW interactions, i.e., no planetary wave source of any kind is prescribed. The present 3D version of the NSM reproduces qualitatively the zonal jets near the tropopause and the accompanying latitudinal temperature variations, which affects the PWs that are generated.

\section{Non-linear Coupling Generated by Gravity Wave Filtering}

Considering that GW processes, in our model, contribute through a number of channels to produce the non-migrating tides as illustrated in Figure 1, it is difficult to completely isolate their specific role in generating the non-linear coupling that is involved. Notwithstanding this problem, we performed a numerical experiment, in which we simply eliminated the GW source after integrating the model sufficiently long to reach equilibrium. The idea was that the inertia in the mean zonal circulation and associated temperature variations $(m=0)$ may be sufficient to maintain nearly at full strength, for some time, the PWs and the migrating tides as well. With similar tidal and PW amplitudes in place, the effect on the non-migrating tides through nonlinear coupling (item 5 in Figure 1) would then become apparent.

To perform this test, the standard computer solution up to 5 model years was started up again to be continued for another 3 months. For comparison, the 5-year model run was started up again, but then it was run for 3 months without the GW source. The amplitudes for the meridional and zonal winds of the $m=1$ migrating diurnal tide are shown in Figure 3 for an altitude of $100 \mathrm{~km}$ at $18^{\circ}$ latitude (Gaussian point) computed with and without $\mathrm{GW}$ forcing. While the zonal winds without GW source are smaller than those with GW interaction, the opposite is true for the meridional winds. These differences are to be expected given the importance of GW processes in general, and they cannot be readily explained. In Figure 4 we show the meridional and zonal winds for $\mathrm{m}=1 \mathrm{PWs}$ computed again with and without GWs, 
represented respectively with solid and dashed lines. The wind velocities for the two solutions are significantly different, but their amplitudes are comparable in magnitude. Finally, the nonmigrating $\mathrm{m}=0$ tide is presented in Figure 5, which is generated by the migrating tide in Figure 3 and by the PWs in Figure 4. This shows that the GW interaction makes a large difference. The amplitudes for this non-migrating tide are much larger for the standard model with $\mathrm{GW}$ forcing. Given that the PW amplitudes are comparable (Figure 4) and the differences in the tides do not reveal a well defined trend in one way or the other (Figure 3), we are led to the tentative conclusion that a significant part of the differences in the non-migrating tide (Figure 5) must be attributed to non-linear coupling by GW filtering (item 5 in Figure 1), illustrated with Figure 2.

The above discussed computer runs clearly show how important GW processes are. But given the many channels in which the waves come into play (Figure 1), we cannot be completely certain about the role GW filtering plays to generate the non-linear interactions involved. For this reason, we have carried out another computer experiment, which specifically targets the GW interaction for the $\mathrm{m}=0$ non-migrating tide. In this case, we ran the standard model for perpetual equinox, with the Sun fixed at the equator. After 18 model months, sufficient to reach equilibrium, we then ran the model in such a way that the GW momentum source for $m=0$ was kept constant. That is, the time dependence was artificially suppressed, which includes variations with a period of 1 day that contribute to generate the $m=0$ non-migrating tide. In this experiment, the time independent $\mathrm{GW}$ momentum source for $\mathrm{m}=0$ is then retained to maintain the global-scale temperature and wind fields that filter the migrating tides and contribute to generate PWs through instabilities. The idea is to produce migrating tides and PWs commensurate with the standard model under the influence GW interactions but without the GW momentum source that generates the $\mathrm{m}=0$ non-migrating tides. Such a model would essentially retain all the GW interactions (1) through (4) in Figure 1, but not the one that accounts for the GW momentum source (5), which specifically contributes to the non-linear coupling that produces the $\mathrm{m}=0$ non-migrating tide.

The results from this computer experiment are presented in Figures 6 though 10 at $18^{\circ}$ latitude, covering a period from 12 to 36 months. In Figure 6, the zonal winds are shown at 80 and $100 \mathrm{~km}$ for the $\mathrm{m}=1 \mathrm{PWs}$, computed (a) with standard GW momentum source and (b) for comparison with the time independent $m=0$ source defined above. For the first 18 months, the solutions are identical, but then they deviate significantly after the time dependent $\mathrm{m}=0$ 
momentum source has been turned off. Without that GW source, we note that the amplitudes are significantly larger, and the same is true for the meridional winds shown in Figure 7. (The differences in amplitude decrease at lower altitudes.) This is an interesting result, not fully understood, which apparently tells us something about the dynamical conditions that are conducive or detrimental to generate PWs in the model -- and we shall come back to discuss it.

Commensurate with the format for the PWs, we present with Figures 8 and 9 the computed diurnal tides for $\mathrm{m}=1$ at $100 \mathrm{~km}$, delineating the total or combined (a), and the westward (b) as well as eastward (c) components. This shows that the dominant westward migrating tides are virtually identical in both cases, with standard and modified $m=0 \mathrm{GW}$ momentum source, which is not surprising. However, with the modified source (Figure 9), the eastward propagating tide (c) is significantly larger than that computed with the standard model (Figure 8), and this is understandable. The eastward propagating tide can be understood to be generated in the model by non-linear coupling between the migrating tide and $m=2$ PWs. And these PWs (not shown) are found to be larger in the case where the $m=0 \mathrm{GW}$ source is forced to be constant, which is consistent with the differences for the $m=1$ PWs apparent from Figures 6 and 7 .

Finally, we present in Figure 10 the non-migrating tides for $m=0$ computed with the standard GW source and, for comparison, with the time independent source applied after 18 months. It shows that the amplitudes are significantly smaller for the case with modified GW source (a), in which the temporal variations are eliminated including the periodicity of 1 day. This decrease in the computed tide occurs in spite of the fact that the PWs in this case are larger than those computed with the standard GW source (comparing Figures 6a and 7a with Figures $6 \mathrm{~b}$ and $7 \mathrm{~b}$ ). Since the $\mathrm{m}=0$ tide is generated by nonlinear coupling between these PWs and the westward migrating tide, and the migrating tides are virtually identical (Figures $8 b$ and $9 b$ ) in both cases, we are thus lead to the conclusion that GWs are indeed playing a major or even dominant role in generating the nonlinear coupling (4) illustrated in Figure 1. In our model, GW processes not only are involved in generating the tides and PWs, they are apparently also involved to produce the non-linear coupling that generates the non-migrating $\mathrm{m}=0$ tide.

\section{Summary and Conclusion}

We demonstrated that non-linear coupling between migrating tides and planetary waves can generate in our model non-migrating tides in the mesosphere that have amplitudes comparable to 
those observed. The dynamical processes involved are affected significantly by GW processes. It is well established that GWs modify the global-scale mean zonal circulation and temperature variations that vary seasonally. This in turn produces through instabilities the PWs in our model. As we had shown earlier, GWs modify and amplify the migrating tides and PWs, which are presently the building blocks of the non-migrating tides in our model.

In this paper, we discussed two computer experiments to show specifically how GWs affect the non-migrating tides that are generated. When the GW momentum source is turned off, the $\mathrm{m}$ $=0$ non-migrating diurnal tide is significantly reduced (Figure 5). Since the GW interaction in this case did not significantly affect the PWs (Figure 4) and did not produce a systematic effect in the zonal and meridional winds of the diurnal tides (Figure 3), the differences in the nonmigrating tide appear to be caused in part by the non-linear coupling (item 5 in Figure 1) associated with GW filtering as illustrated in Figure 2.

In the second case, the model was run for perpetual equinox with the Sun fixed at the equator. For comparison, the time dependence of the $\mathrm{m}=0 \mathrm{GW}$ momentum source was then artificially suppressed to investigate its effect on the non-linear coupling. As expected, this modification did not affect the migrating diurnal tide for $m=1$ (Figures 8 and 9), but it produced a significant increase in the PW amplitudes at high altitudes above $80 \mathrm{~km}$ (Figures 6 and 7). In spite of this increase, the effect on the non-migrating $m=0$ tide was that its magnitude decreased significantly (Figures 10). This leads to the conclusion that GW filtering of the kind illustrated in Figure 2 contributed significantly to the nonlinear coupling between migrating tide and PWs, which generates the nonmigrating $\mathrm{m}=0$ tide. And the same may hold for the other nonmigrating tides.

The question is what causes the reduction in the PW amplitudes (Figures 6 and 7), which is associated with the time dependence in the $\mathrm{m}=0 \mathrm{GW}$ momentum source that was artificially suppressed in the above discussed computer experiment. Formulating the question differently, one may ask why the time dependence of the $\mathrm{m}=0 \mathrm{GW}$ momentum source interferes with the instabilities that generate the PWs in the model. We do not have a good answer but believe that the following might be happening. With the time independent steady $m=0 \mathrm{GW}$ source, the baroclinic instability can fully develop to generate PWs. But when the time dependent variations of this source (with a period of 1 day included) are involved, this instability is disturbed or partially broken up. The consequence is then that the PWs are weakened. One could argue 
perhaps that a sort of conservation principle is involved. As there is no free lunch, the nonmigrating tides are being generated in part at the expense of the PWs. With GW momentum conserved in the Doppler Spread Parameterization, wave filtering apparently contributes significantly to the non-linear coupling that is involved to produce closure.

\section{References}

Akmaev, R. A., Simulation of large-scale dynamics in the mesosphere and lower thermosphere with the Doppler-spread parameterization of gravity waves: 2. Eddy mixing and the diurnal tide, J. Geophys. Res., in press, 2000

Akmaev, R. A., J. M. Forbes, and M. E. Hagan, Simulation of tides with a spectral mesosphere/lower thermosphere model, Geophys. Res. Lett., 23, 2173, 1996

Avery, S. K., R. A. Vincent, A. Phillips, A. H. Manson, and G. R. Fraser, High latitude tidal behavior in the mesosphere and lower thermosphere, J. Atm. Terr. Phys., 51, 595, 1989

Burrage M. D., M. E. Hagan, W. R. Skinner, D. L. Wu, and P. B. Hays, Long-term variability in the solar diurnal tide observed by HRDI and simulated by the GSWM, Geophys. Res. Lett., 22, 2641, 1995a

Burrage M. D., D. L. Wu, W. R. Skinner, D. A. Ortland, and P. B. Hays, Latitude and seasonal dependence of the semidiurnal tide observed by the high-resolution Doppler imager, $J$. Geophys. Res., 100, 11313, 1995b

Chan, K. L., H. G. Mayr, J. G. Mengel, and I. Harris, A 'stratified' spectral model for stable and convective atmospheres, J. Comp. Phys., 113, 165, 1994a

Chan, K. L., H. G. Mayr, J. G. Mengel, and I. Harris, A spectral approach for studying middle and upper atmospheric phenomena, J. Atmos. Terr. Phys., 56, 1399, 1994b

Chapman, S., and R. S. Lindzen, Atmospheric Tides, D. Reidel, Hingham, MA, 1970

Forbes, J. M., and H. B. Garrett, Thermal excitation of atmospheric tides due to insolation absorption by $\mathrm{O}_{3}$ and $\mathrm{H}_{2} \mathrm{O}$, Geophys. Res. Lett., 5, 1013, 1978

Forbes, J. M, and M. E. Hagan, Diurnal propagating tides in the presence of mean winds and dissipation: a numerical investigation, Planet. Space Sci., 36, 579, 1988

Forbes, J. M., and F. Vial, Monthly simulations of solar semidiurnal tide in the mesosphere and lower thermosphere, J. Atm. Terr. Phys., 51, 649, 1989 
Forbes, J. M, J. Gu, and S. Miyahara, On the interactions between gravity waves and the diurnal propagating tide, Planet. Space Sci., 39, 1249, 1991

- Forbes, J. M., Tidal and planetary waves, Geophysical Monograph 87, 67, 1995

Fritts, D. C., Gravity wave-tidal interactions in the middle atmosphere: observations and theory, Geophysical Monograph 87, 89, 1995a

Fritts, D. C., Gravity wave forcing and effects in the mesosphere and lower thermosphere, Geophysical Monograph 87, 121, 1995b

Geller, M. A., V. A. Yudin, B. V. Khattatov, and M. E. Hagan, Modeling the diurnal tide with dissipation derived from UARS/HRDI measurements, Ann. Geophys., 15, 1198, 1997

Hagan, M. E., Comparative effects of migrating solar sources on tidal signatures in the middle and upper atmosphere, J. Geophys. Res., 101, 21213, 1996

Hagan, M. E., J. M. Forbes, and F. Vial, On modeling migrating solar tides, Geophys. Res. Lett., 22, 893, 1995

Hays, P. B. et al. The high-resolution Doppler imager on the Upper Atmosphere Research Satellite, J. Geophys. Res., 98, 10,713, 1993

Hays, P. B., D. L. Wu, and the HRDI science team, Observations of the diurnal tide from space, J. Atmos. Sci., 51, 3077, 1994

Hines, C. O., Doppler-spread parameterization of gravity-wave momentum deposition in the middle atmosphere, 1, Basic formulation, J. Atmos. Solar Terr. Phys., 59, 371, 1997a

Hines, C. O., Doppler-spread parameterization of gravity-wave momentum deposition in the middle atmosphere, 2 , Broad and quasi monochromatic spectra, and implementation, $J$. Atmos. Solar Terr. Phys., 59, 387, 1997b

Jacobi, C. et al., Mesopause region semidiurnal tide over Europe as seen from ground-based wind measurements, Adv. Space Res., 24, 1545, 1999

Lindzen R. S., Turbulence and stress due to gravity wave and tidal breakdown, J. Geophys., Res., 86, 9707, 1981

Lindzen, R. S., and S. Hong, Effects of mean winds and horizontal temperature gradients on solar and lunar semidiurnal tides in the atmosphere, J. Atm. Sci., 31, 1421, 1974

Manson, A. H., C. E. Meek, H. Teitelbaum, F. Vial., R. Schminder, D. Kuerschner, M. J. Smith, G. J. Fraser, and R. R. Clark, Climatology of semi-diurnal and diurnal tides in the middle atmosphere (70-110 km) at middle latitudes (40-550), J. Atm. Terr. Phys., 51, 579, 1989 
Mayr, H. G., J. G. Mengel, K. L. Chan, and H. S. Porter, Mesosphere dynamics with gravity forcing: Part I, Diurnal and semi-diurnal tides, J. Atm. Solar-Terr. Phys., 63, 1851, 2001a

Mayr, H. G., J. G. Mengel, K. L. Chan, and H. S. Porter, Mesosphere dynamics with gravity forcing: Part II, Planetary waves, J. Atm. Solar-Terr. Phys., 63, 1865, 2001b

Mayr, H. G., J. G. Mengel, C. A. Reddy, K. L. Chan, and H. S. Porter, Properties of QBO and SAO generated by gravity waves, J. Atm. Solar-Terr. Phys., 63, 1135, 2000

Mayr, H. G., J. G. Mengel, K. L. Chan, and H. S. Porter, Seasonal variations and planetary wave modulation of diurnal tides influenced by gravity waves, Adv. Space Res., 24, 1541, 1999a

Mayr, H. G., J. G. Mengel, C. A. Reddy, K. L. Chan, and H. S. Porter, The role of gravity waves in maintaining the QBO and SAO at equatorial latitudes, Adv. Space Res., 24, 1531, 1999b

Mayr, H. G., J. G. Mengel, K. L. Chan, and H. S. Porter, Seasonal variations of the diumal tide induced by gravity wave filtering, Geophys. Res. Lett., 25, 943, 1998

McLandress, C., G. G. Shepherd, and B. H. Solheim, Satellite observations of thermospheric tides: Results from the Wind Imaging Interferometer on UARS, J. Geophys. Res., 101, 4093, 1996

McLandress, C., Seasonal variability of the diurnal tide: Results from the Canadian Middle Atmosphere General Circulation Model, J. Geophys. Res., 102, 29747, 1997a

McLandress, C., Sensitivity studies using the Hines and Fritts gravity wave drag parameterization, NATO ASI Series, Vol. I 50, 245, 1997b

Miyahara, S., and J. M. Forbes, Interactions between gravity waves and the diurnal tide in the mesosphere and lower thermosphere, J. Meteor. Soc. Japan, 69, 523, 1991

Norton, W. A., and J. Thuburn, The two-day wave in a middle atmosphere GCM, Geophys. Res. Lett., 23, 2113, 1996

Norton, W. A., and J. Thuburn, Sensitivity of mesospheric mean flow, planetary waves and tides to strength of gravity wave drag, J. Geophys. Res., 104, 30,897, 1999

Plumb, R. A., Baroclinic instability of the summer mesosphere: A mechanism for the quasi-2day wave?, J. Atmos. Sci., 40, 262, 1983

Shepherd, G. G., et al., WINDII, the Wind Imager Interferometer on the Upper Atmosphere Research Satellite, J. Geophys. Res., 98, 10,7725, 1993

Talaat, E. R., and R. Lieberman, Nonmigrating diurnal tides in mesospheric and lower thermospheric winds and temperatures J. Atmos. Sci., 56, 4073, 1999 
Strobel, D. F., Parameterization of atmospheric heating rate from 15 to $120 \mathrm{~km}$ due to $\mathrm{O} 2$ and $\mathrm{O} 3$ absorption of solar radiation, J. Geophys. Res., 83, 7963, 1978

Vial, F., and J. M. Forbes, Recent progress in tidal modeling, J. Atm. Terr. Phys., 51, 663, 1989

Vincent, R. A., T. Tsuda, and S. Kato, Asymmetries in mesospheric tidal structure, J. Atm. Terr. Phys., 51, 609, 1989

Volland, H., Atmospheric Tidal and Planetary Waves, Kluwer Academic Publ., Boston, MA, 1988

Yudin, V. A., B. V. Khattatov, M. A. Geller, et al.. Thermal tides and studies to tune the mechanistic tidal model using UARS observations, Ann. Geophys., 15, 1205, 1997

\section{Figure Captions}

Figure 1: Schematic, reproduced from Figure 19 in Part I with greater emphasis on gravity wave (GW) processes, which illustrates the dynamical features and processes that are involved in generating the non-migrating tides.

Figure 2: Schematic, to show how GW filtering can be involved to generate the non-linear coupling that produces non-migrating tides from planetary waves (PW) and migrating tides as illustrated with item 5 in Figure 1.

Figure 3: Diurnal tides for meridional (a) and zonal (b) winds at $100 \mathrm{~km}$ and $18^{\circ}$ latitude, computed for a time period following solstice after 5 model years (60 months). The standard model is presented in solid lines, and for comparison a solution is shown in dotted lines in which the GW source is suppressed (reduced by a factor of 30 ). The differences are significant, but they are not systematic to indicate that one or the other solution produces a significantly larger tide.

Figure 4: Analogous to Figure 3 but for the $\mathrm{m}=1 \mathrm{PWs}$ computed with (solid lines) and without (dotted lines) GW forcing.

Figure 5: Analogous to Figure 3 but for the $\mathrm{m}=0$ non-migrating diurnal tide that is generated by non-linear coupling between migrating tide (Figure 3) and PWs (Figure 4). The differences are large and reveal the importance of GW interactions. Since the differences for the tides (Figure 3) and PWs (Figure 4) are relatively small, this suggests that the GWs are important for the nonlinear coupling. 
Figure 6: Zonal winds for planetary waves with $\mathrm{m}=1$ at 80 and $100 \mathrm{~km}$ and at $18^{\circ}$ latitude computed for perpetual equinox. The standard solution (a) accounts for the full $\mathrm{GW}$ momentum source. For comparison, a solution is presented (b) in which the GW momentum is modified after 18 months so that the time dependence for $\mathrm{m}=0$ is artificially eliminated. In the latter case, the amplitudes are then considerably larger (after 18 months), which is interesting but not yet fully understood.

Figure 7: Analogous to Figure 6 but for the meridional winds.

Figure 8: Diurnal tides for $\mathrm{m}=1$ computed with the standard $\mathrm{GW}$ momentum source.

Figure 9: Analogous to Figure 8 but computed with the modified GW momentum source after 18 months. Note that the westward migrating tide (b) is similar in magnitude to that in Figure 8(b). But the amplitudes for the eastward migrating tide (c) are larger (after 18 months) because the associated PWs for $\mathrm{m}=2$ (not presented) are also stronger, which is consistent with the differences for the $m=1$ PWs shown in Figures 6 and 7 .

Figure 10: (a) Diurnal tides for $\mathrm{m}=0$, generated by non-linear interactions between PWs and migrating tides. With the standard GW momentum source (a), the PWs involved are represented in Figures 6(a) and 7(a), and the migrating tide in Figure 8(b). (b) For comparison a solution is presented with a source in which the time dependence of the $\mathrm{m}=0 \mathrm{GW}$ momentum source is eliminated, including the 1-day periodicity. In this case (b), the PWs involved are represented in Figures 6(b) and 7(b), and the migrating tides in Figure 9(b). Note that the $m=0$ tides in (b) are much weaker than in (a) although the PWs involved are significantly stronger, which is interpreted as evidence for the importance of GW induced non-linear coupling. 


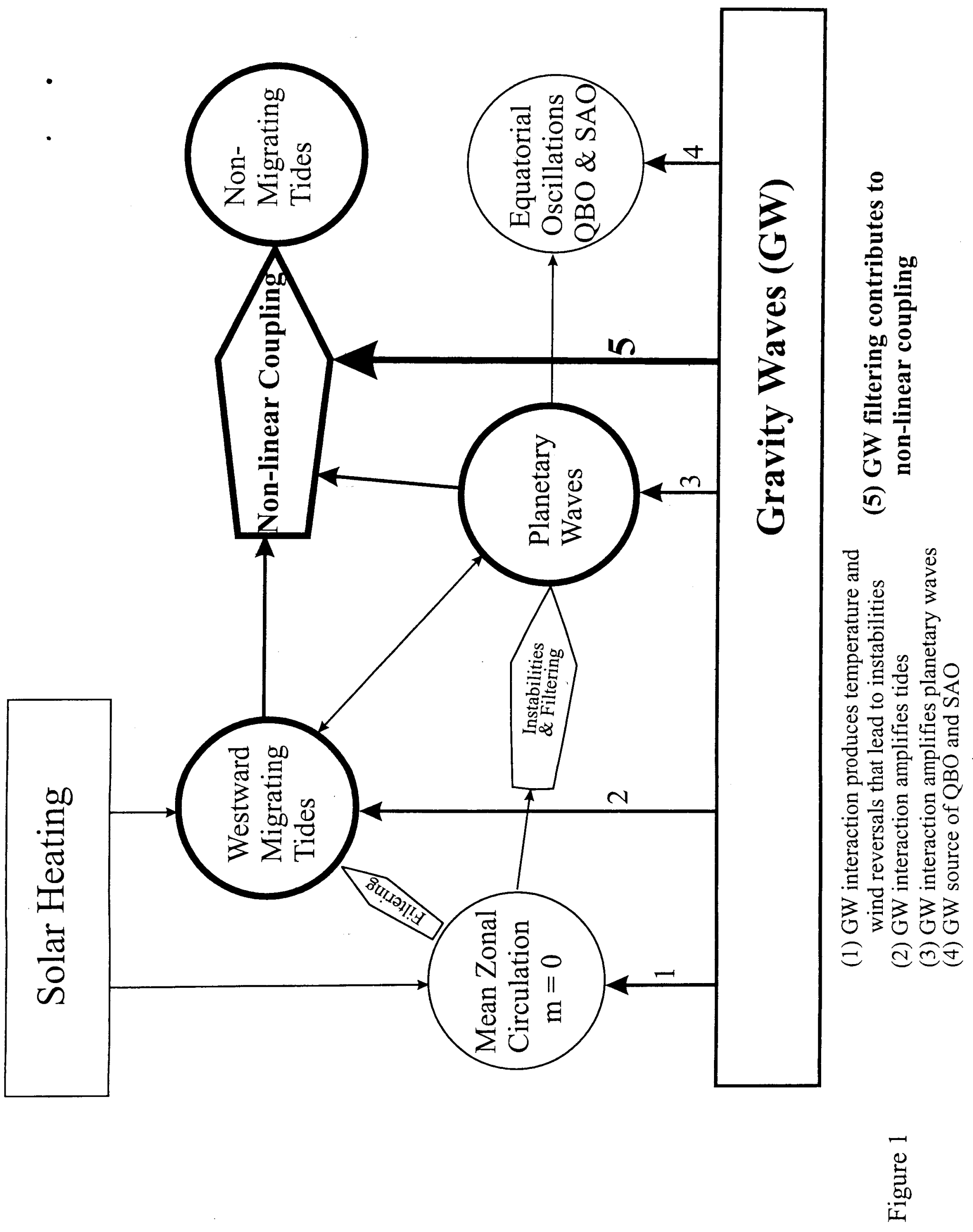




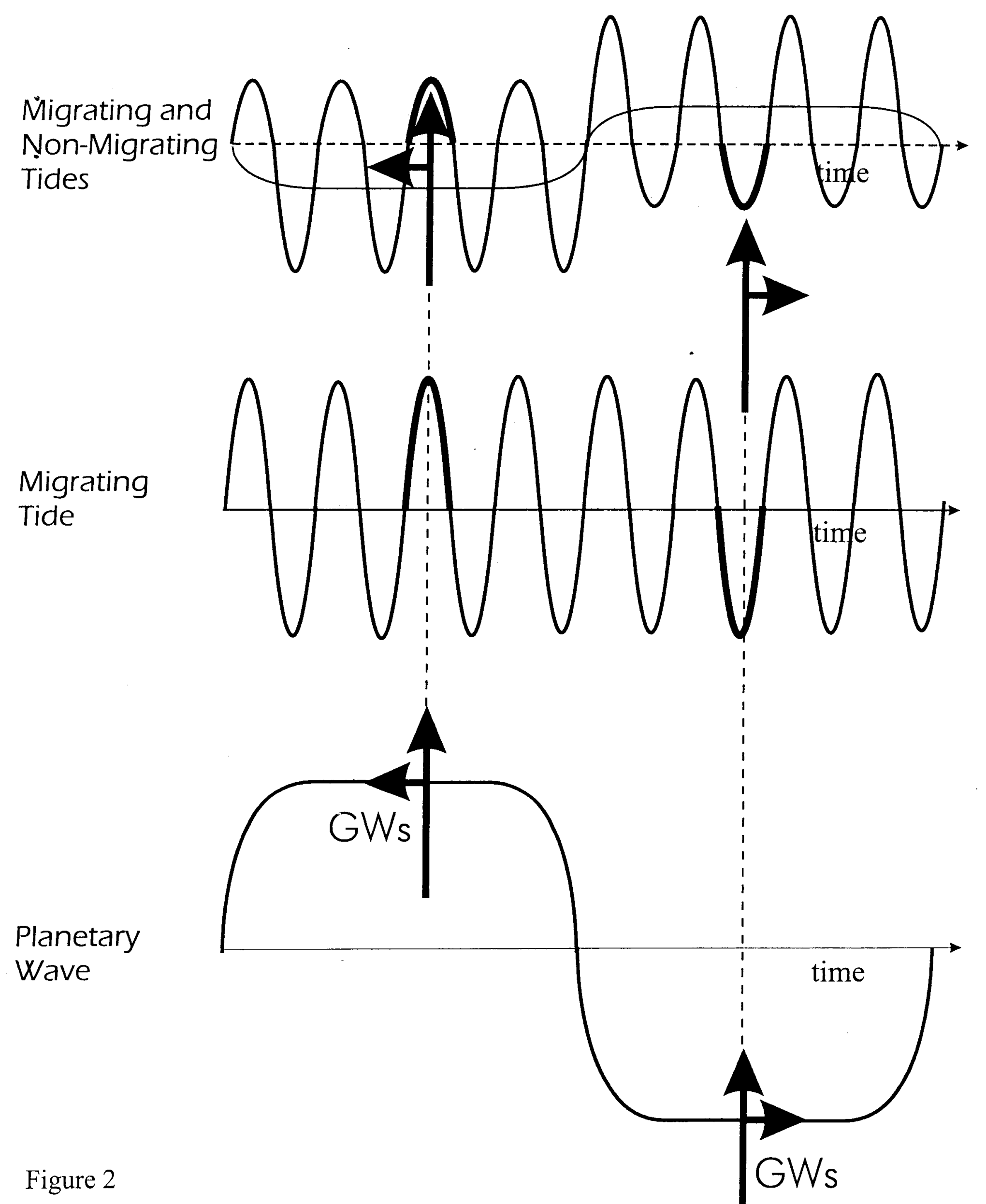



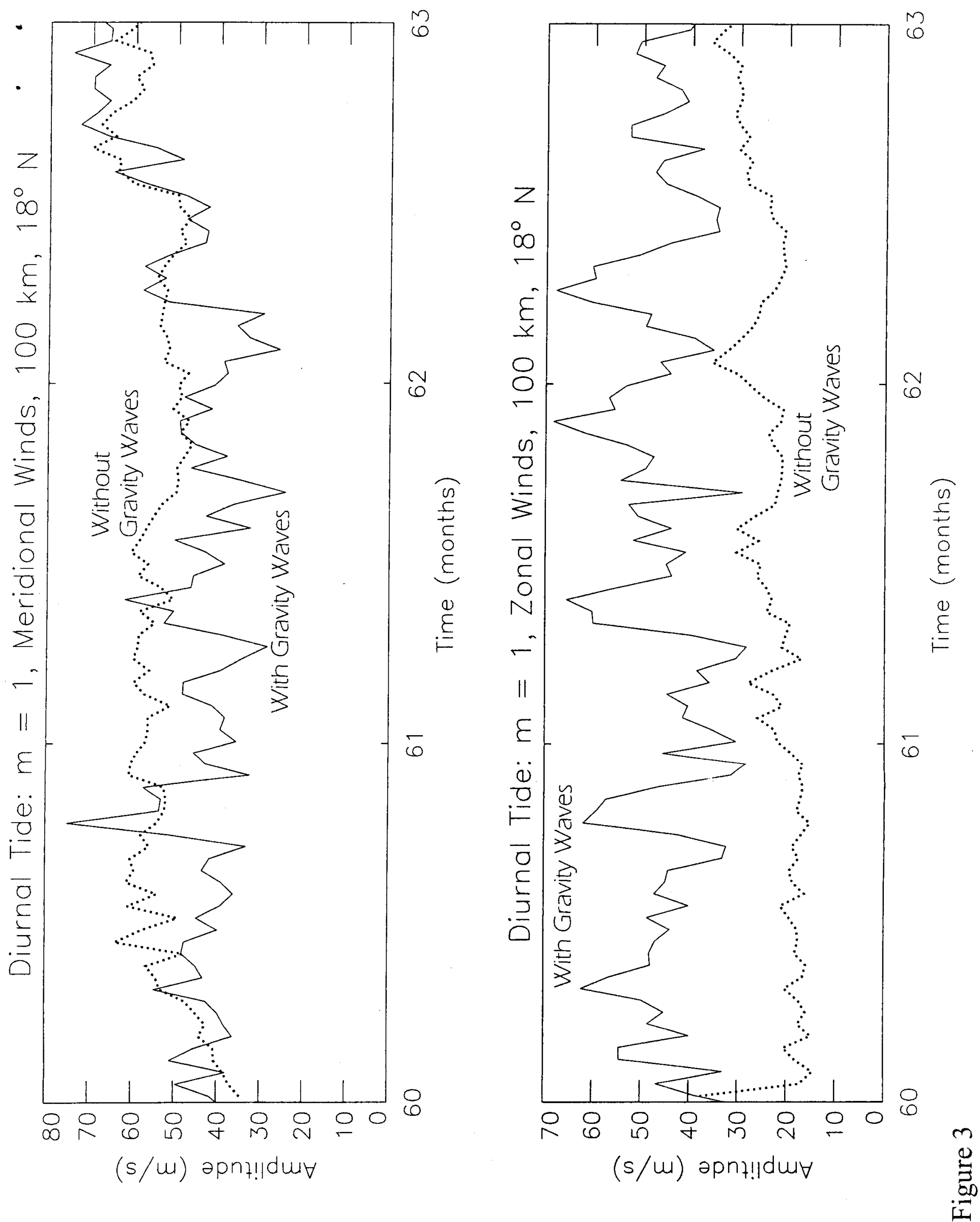

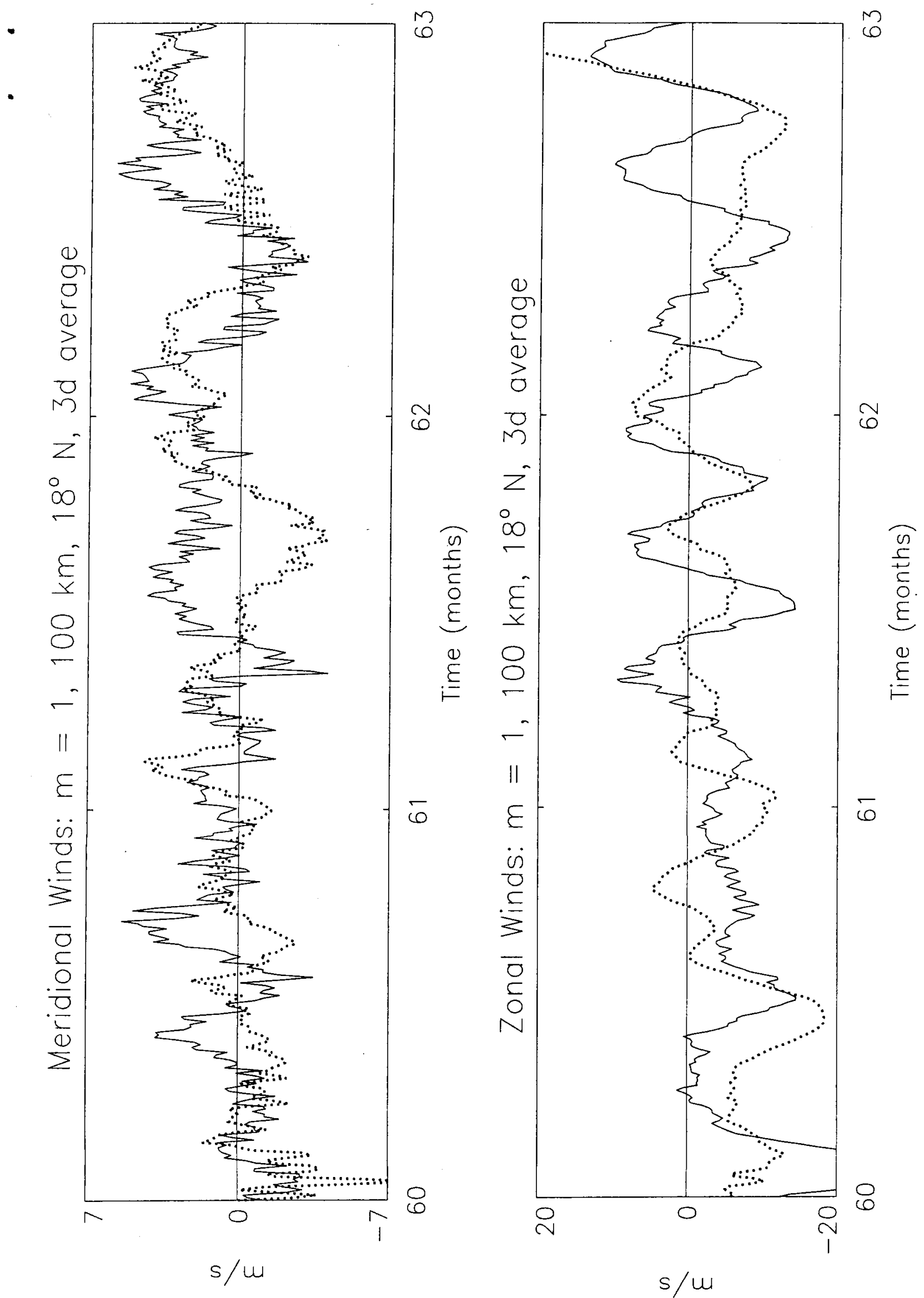
م
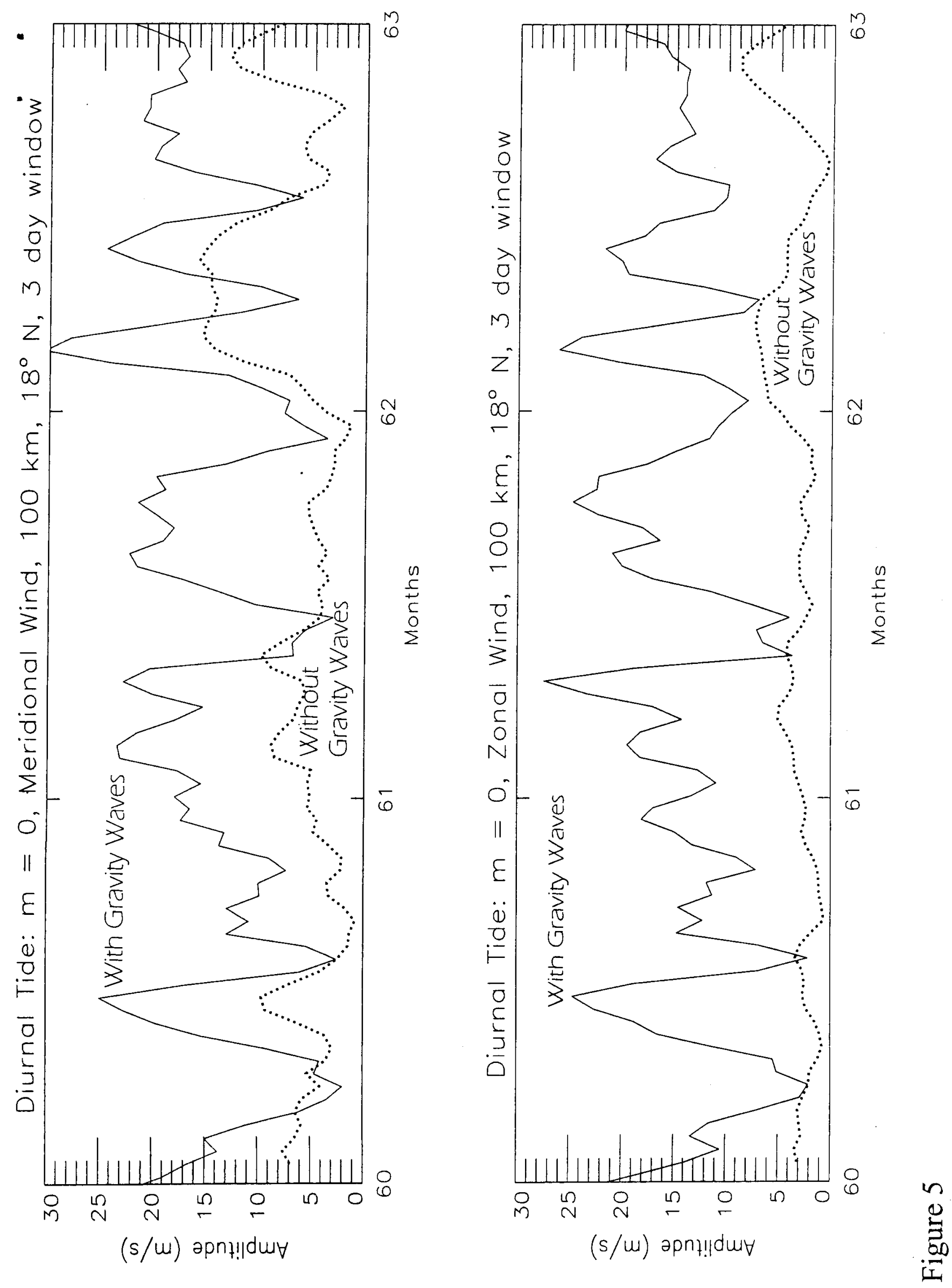


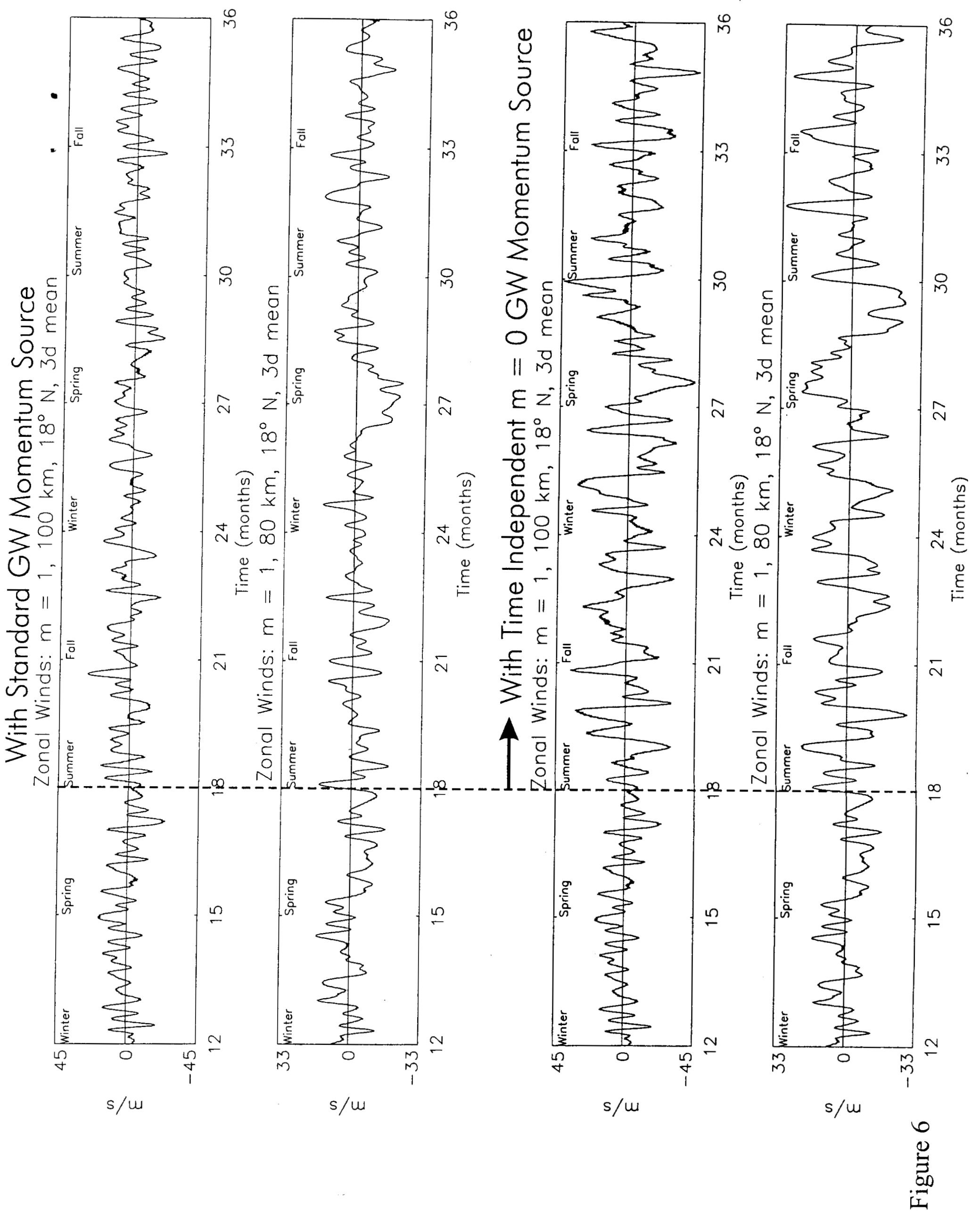




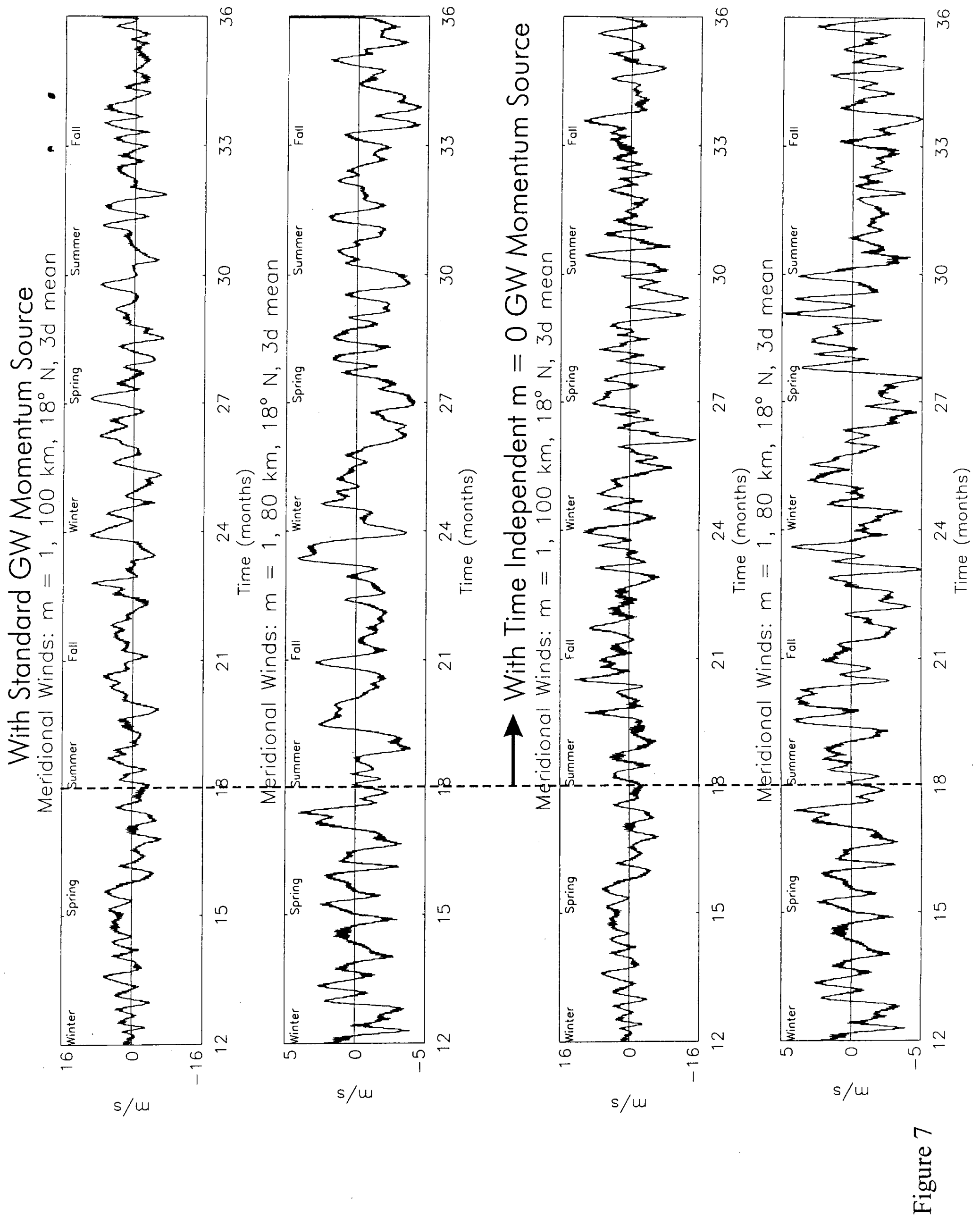




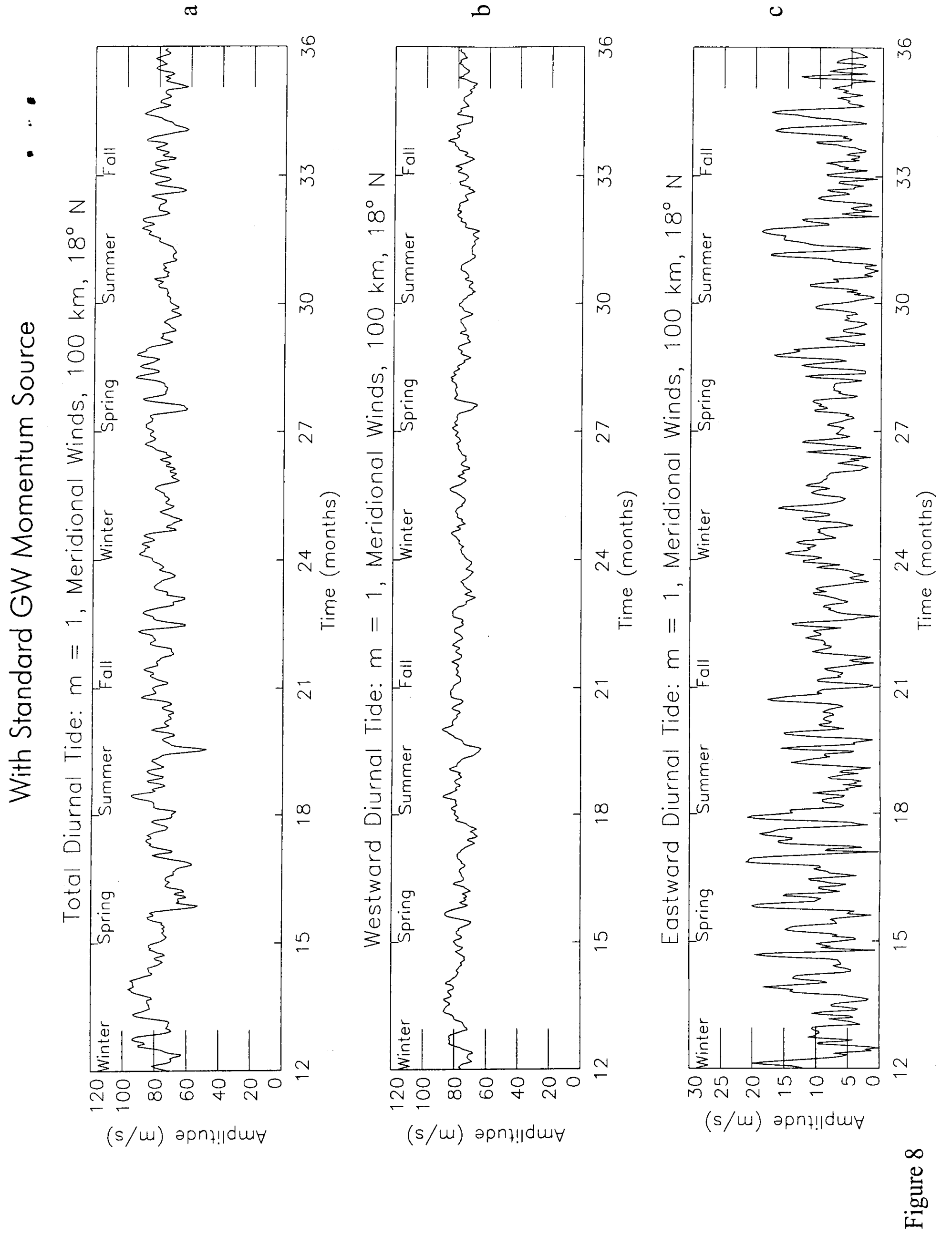




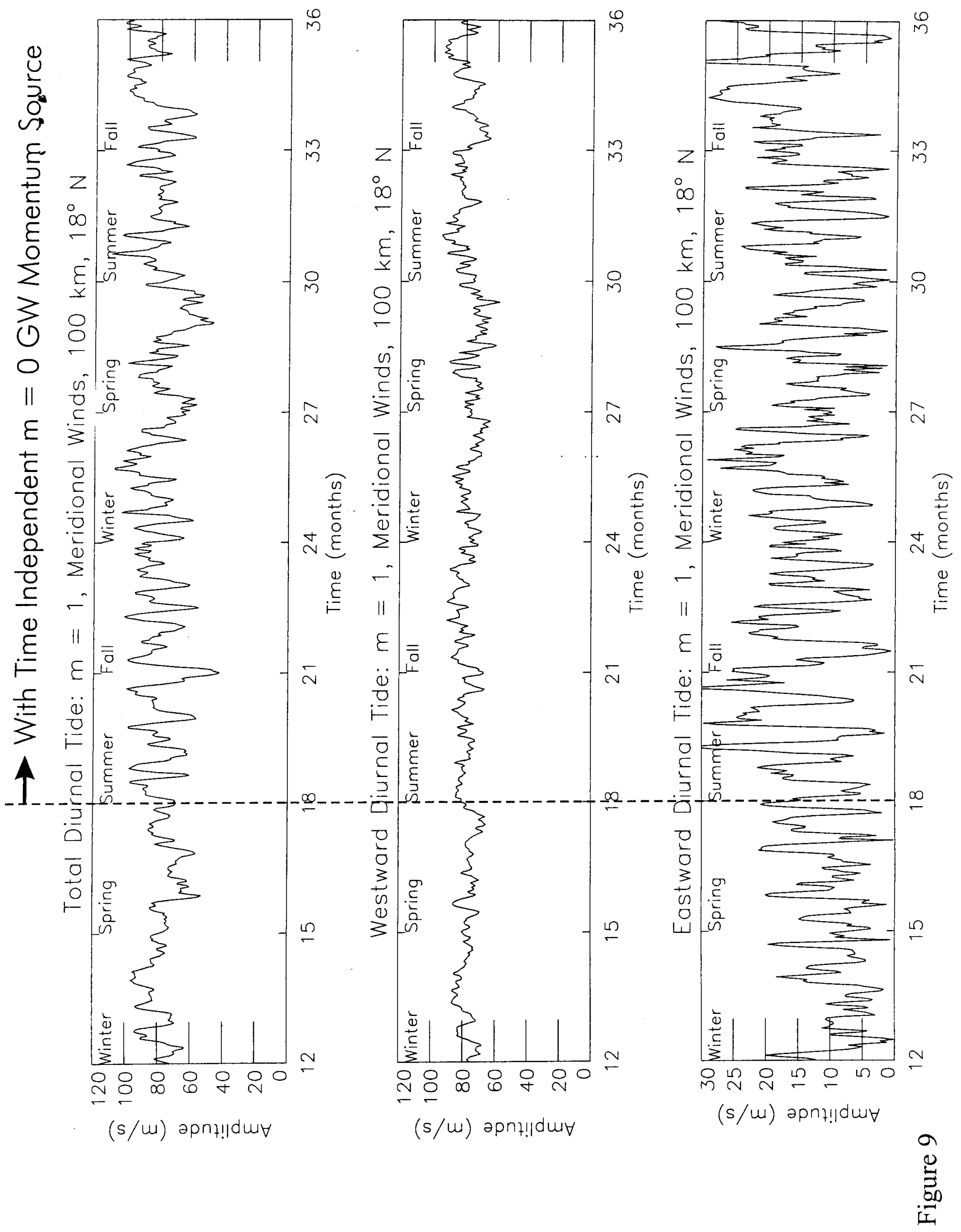




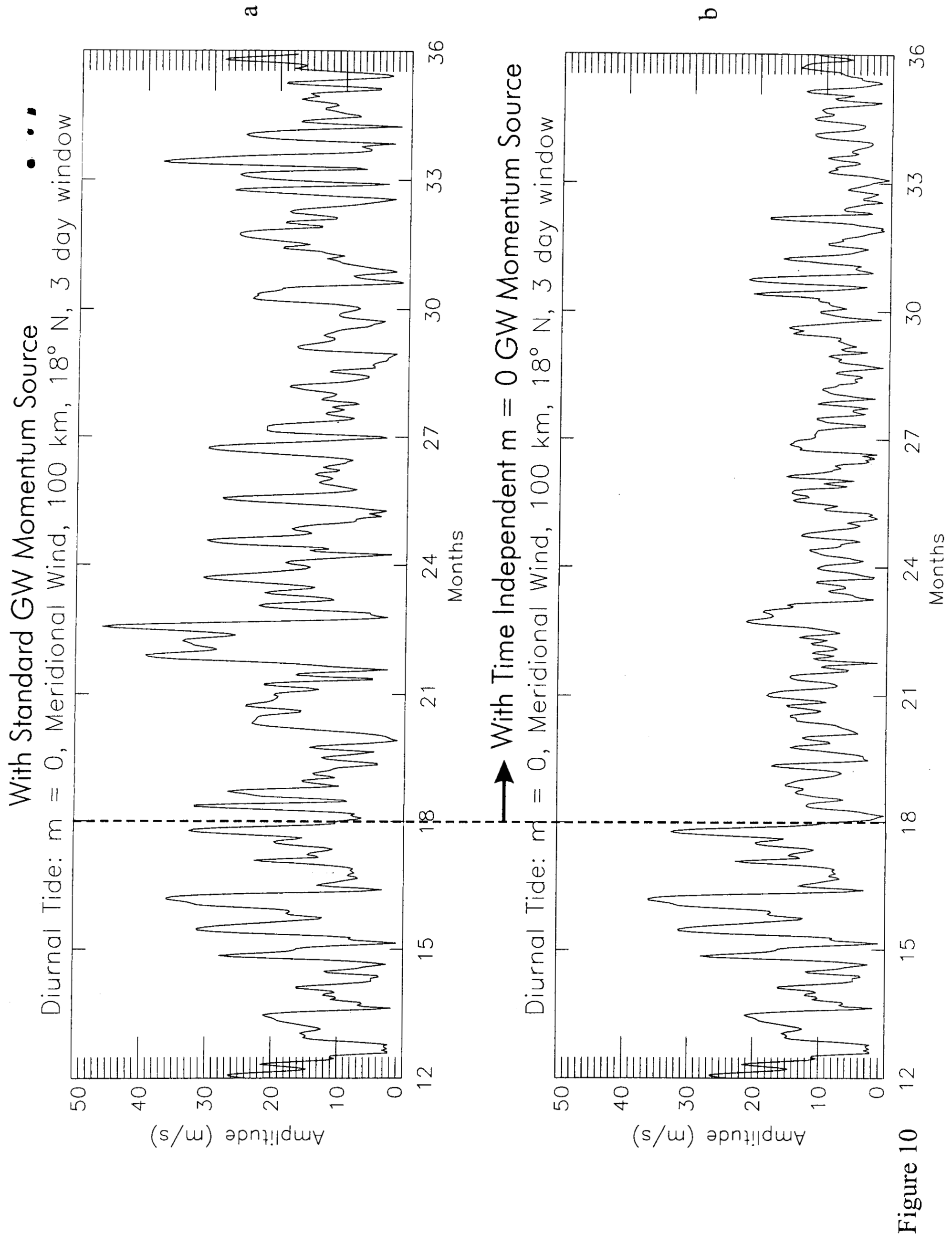

